УДК 314.012:332.135 (571.56)

ПРОБЛЕМЫ ТЕРРИТОРИАЛЬНОЙ КОНЦЕНТРАЦИИ НАСЕЛЕНИЯ И МОНОГОРОДА В СЕВЕРНОМ РЕГИОНЕ (НА ПРИМЕРЕ РЕСПУБЛИКИ САХА (ЯКУТИЯ))

татьяна C. Мостахова ${ }^{1, @}$

\author{
${ }^{1}$ Якутский научный цеентр Сибирского отделения РАН, 677000, Россия, г. Якутск, ул. Петровского, 2 \\ @mostakhovats@mail.ru
}

Поступила в редакциюю 19.02.2018. Принята к печати 27.03.2018.

Ключевые слова: пространственное развитие, расселение, северный регион, моногорода, Республика Саха (Якутия).

\begin{abstract}
Аннотация: Расселение населения представляется значимым фактором устойчивого развития территории. Диспропорции, сформированные в течение определенного периода времени в пространственном развитии, касающиеся главным образом диспропорций центра и периферии, городских и сельских поселений, актуализируют внимание к процессам расселения населения, выявлению перспектив их развития.

На протяжении последних десятилетий основной тенденцией в расселении выступает стягивание населения к центру и отрицательная динамика периферийных территорий. Глубинные трансформационные изменения в России, совпавшие со значительными демографическими переменами, привели к усилению дихотомии между фокусными точками и провинцией.

В северных и арктических регионах это выражается в сокращении числа населенных пунктов, как городских, так и особенно сельских. Разрежение поселенческой сети, углубление территориальной концентрации населения приводят к еще большему обезлюдению пространства. На фоне свертывания сельского расселения происходят изменения в городском расселении, где значительную долю имеют моногорода. Нестабильность градообразующей базы создает угрозы демографическому потенциалу моногородов.

Моногорода, возникновение которых на Севере связано со спецификой регионального развития территорий, ориентированного на добычу природных ресурсов стратегического значения, не должны оцениваться только как несостоятельная форма пространственной организации населения. Сохранение ориентации на сырьевую экономику, которая по-прежнему остается основным подходом в развитии северных и арктических территорий, вряд ли будет способствовать как диверсификации экономики, так и созданию условий для комплексного развития системы расселения, в том числе и моногородов.
\end{abstract}

Для цитирования: Мостахова Т. С. Проблемы территориальной концентрации населения и моногорода в северном регионе (на примере Республики Саха (Якутия)) // Вестник Кемеровского государственного университета. 2018. № 1. С. 28-32. DOI:10.21603/2078-8975-2018-1-28-32.

Значимым фактором устойчивого развития территории можно оценивать расселение населения, т. е. его пространственную организацию. Система населенных пунктов, организованная в поселенческий каркас, выступает той отправной точкой, от которой выстраиваются векторы дальнейшего территориального развития. Диспропорции, сформированные в течение определенного периода времени в пространственном развитии, касающиеся главным образом диспропорций центра и периферии, городских и сельских поселений, актуализируют внимание к процессам расселения населения, выявлению перспектив их развития.

На протяжении последних десятилетий основной тенденцией в расселении выступает стягивание населения к центру и отрицательная динамика периферийных территорий [1]. Усиление концентрации населения в рамках модели «центр-периферия» пред- ставляет основную региональную специфику для северных территорий; это касается прежде всего сельского расселения. Следует отметить, что динамика развития сельских и городских поселений, в том числе и моногородов, тесно связана и взаимообусловлена, несмотря на кажущуюся взаимонезависимость и противоречивость их развития.

Присутствие центростремительных векторов в динамике сельских поселений, которые по существу определяют устойчивость поселенческого каркаса, выражается в сокращении числа населенных пунктов. Сельским территориям в современных условиях присуще сильное экономическое сжатие, обусловленное такими процессами, как рост доли убыточных сельских предприятий, сокращение бюджетной поддержки сельского хозяйства, деградация сельской инфраструктуры. Разрежение поселенческой сети, углубление территориальной концентра- 
ции населения приводят к еще большему обезлюдению пространства.

Специфика пространственной дифференциации расселения республики вполне вписывается в рамки модели «центр-периферия»: с удалением от более заселенной центральной части снижаются плотность населения, размер и густота населенных пунктов. Расширение сети поселений, характерное для предшествующего периода экстенсивного освоения Севера, проявлялось в увеличении числа городских поселений, практически до переписи 1989 г. Если в 1959 г. в Якутии насчитывалось 48 городских населенных пунктов (городов и поселков городского типа), то к 1989 г. их число возросло до 78, т. е. практически в 1,6 раза. Для сельского же расселения было характерно присутствие иного тренда, а именно - сокращение числа поселений. В 1959 г. в республике было 4423 села, к 1989 г. их число уменьшилось до 719 , т. е. более чем в 6 раз.

Процесс сокращения поселенческого каркаса в последующие годы распространился и на городское расселение. К 2010 г. число городских населенных пунктов сократилось до 55 (почти в 1,5 раза), а сельских - до 586 , т. е. в 1,2 раза [2]. Таким образом, по темпам сокращения городское расселение «опередило» сельское.

Отмечаемое «стягивание» сельского расселения выражает такое фундаментальное свойство географического пространства, как концентрация, которое выражается в наличии, с одной стороны, множества густонаселенных районов, а с другой стороны, обширных территорий практически без постоянного населения.

Сжатие поселенческого каркаса количественно можно отразить в таком показателе, как индекс территориальной концентрации, рассчитываемый как доля (в \%) территории наиболее плотнонаселенных районов, сосредоточивающих 50 \% всего ее населения, в общей площади региона [3]. В республике за 2002-2010 гг. территориальная концентрация усилилась практически в 1,5 раза. По данным за 2010 г. половина населения региона проживает всего на 4,07 \% территории (для сравнения, в 2002 г. - на 6 \%).

Число городских населенных пунктов сокращается за счет поселков городского типа - с 55 до 42. Среди них более всего уменьшилось число поселений с людностью от 10 до 20 тыс. человек и от 3 до 5 тыс. человек. Особенностью городского расселения Якутии является то, что некоторые из городов сохраняют свой городской статус только в силу историко-географических обстоятельств, по существу не имея необходимой для статуса города численности населения. Более 69 \% всего числа городов занимают поселения с численностью от 5 до 50 тыс. человек. Наблюдается, таким образом, исторически сложившееся несоответствие между рангами «город», «поселок городского типа» и критерием «людность» [4].

Половина населения проживает в больших городах людностью свыше 100 тыс. человек. В поселках городского типа основная часть жителей (61,2%) также сосредоточена в более крупных поселениях людностью свыше 10 тыс. человек, которые представляют собой фактически малые города.

Наибольшую густоту городское расселение имеет в районах т. н. старопромышленного освоения.

Особенности городского расселения в республике подтверждают справедливость выводов Л. Б. Карачуриной и Н. В. Мкртчяна о том, что региональные процессы действуют менее однозначно, чем это следует из классической теории Дж. Фридмана «центр-периферия», согласно которой кристаллизация массы вокруг ядра приводит к расплыванию границ ядра и усилению его силы (мощности) [5]. Вследствие неравномерности экономического роста и процессов пространственной поляризации неизбежно возникают диспропорции между центром и периферией. Однако на уровне отдельных регионов абсолютные и однозначные «центры» не возникают, а наблюдается многослойность пространства, множественность ядер и периферий поляризации. И в Республике Саха (Якутия) столица г. Якутск не выступает единственным центром притяжения и поляризации.

Городские поселения можно считать ядрами кристаллизации опорной сети расселения, в то время как сельские поселения следует расценивать как элементы расселения, придающие устойчивость этой сети. К сожалению, современная динамика сельского расселения не показывает развитие этой устойчивости, характеризуясь сокращением сельских поселений, что было отмечено ранее.

Размещение сельского населения имеет более ощутимые территориальные различия по сравнению с городским расселением. Плотность городского расселения определяется, прежде всего, их зависимостью от наличия очагов промышленного освоения. А сельское расселение в большей степени зависит от сельскохозяйственной освоенности территории, природно-климатических условий, особенностей рельефа и гидрографической сети. Вследствие этого сельский поселенческий каркас имеет явную картину тяготения поселений от периферии к центру.

Сжатие сельского поселенческого каркаса и сокращение городских населенных пунктов по существу имеют один главный фактор, а именно - миграционные процессы. Им присуща особая значимость в формировании населения северных регионов и сохранении демографической безопасности региона. В силу более высокой степени реагирования на те или иные факторы миграционные процессы активно и быстро воздействуют на демографическую ситуацию, изменяя численность населения, структуру населения по возрасту и полу, другие демографические характеристики, в том числе и, пожалуй, в первую очередь, на размещение населения. Это их главное отличие от процессов естественного воспроизводства населения, которое обладает в достаточной степени инерционным характером.

В начале процесса хозяйственного освоения территории Якутии миграция являлась главным источником роста численности населения на Севере, в том числе и в Республике Саха (Якутия). Наибольшие 
показатели миграционного сальдо в республике регистрировались в 70-х - 80-х гг., что было обусловлено интенсивным промышленным строительством. В 90-е гг. в регионе стало отмечаться отрицательное миграционное сальдо. Миграционный отток был настолько существенным, что стало регистрироваться сокращение общей численности населения региона. Тенденции пространственного развития реализуются в миграционных потоках, через которые, собственно говоря, и происходит трансформация пространства, изменения в территориальном распределении и производства, и населения, и мест его локализации (населенных пунктов).

В результате на фоне свертывания сельского расселения стали отмечаться и существенные изменения в городском расселении, где значительную долю имеют моногорода. Нестабильность градообразующей базы создала определенные угрозы демографическому потенциалу в городской местности, в том числе и для моногородов.

Большая часть городских поселений Якутии была монопрофильной, что было обусловлено горнодобывающей специализацией региона. Городское поселение при горнодобывающем предприятии - это самый распространенный тип городского поселения региона.

Интенсивное промышленное освоение природно-ресурсного потенциала Якутии в советское время проходило более быстрыми темпами, чем создание институтов государственного управления. Новые территории хозяйственного освоения не имели других субъектов, способных предоставить минимальный спектр социальных услуг. Монопрофильные поселения Севера становились своеобразными ядрами концентрации в системе расселения. Новые экономические условия привели к длительной стагнации монофункциональных систем расселения, которая обострилась в период кризиса 2008-2009 гг. Одним из проявлений этой стагнации стало обострение проблемы сокращения городского населения, оказавшееся особенно катастрофическим для северной системы расселения. Многие монофункциональные поселения Севера утратили градообразующую основу в связи с закрытием горнодобывающих предприятий. Следует подчеркнуть, что большинство городов и поселков городского типа можно отнести к монопрофильным поселениям, учитывая специфику формирования поселенческого каркаса в северных регионах.

Проблемы в развитии расселения в целом и в развитии монопрофильных поселений обусловили разработку специального проекта по развитию моногородов. В Республике Саха (Якутия) в проекте «Моногорода» участвуют 6 населенных пунктов - Мирный, Айхал, Удачный, Нерюнгри, Нижний Куранах и Мохсоголлох. Градообразующими предприятиями для них выступают АК «АЛРОСА», ХК «Якутуголь», АО «Алданзолото ГРК» и АО «Якутцемент». В рамках программы «Комплексное развитие моногородов» планируется создать в этих населенных пунктах территории опережающего социально-экономического развития, реализовать муниципальные программы поддержки ма- лого и среднего предпринимательства. Для поддержки комплексного развития в моногородах предусмотрено субсидирование строительства объектов для инвестиционных проектов, квоты для подготовки медицинских и педагогических кадров и др. меры. В г. Нерюнгри к 2020 г. будет создан индустриальный парк «Нерюнгринский», в п. Удачный - предприятие по переработке молочной и кисломолочной продукции. В г. Мирный планируется развитие инженерной инфраструктуры для индивидуального жилищного строительства, производство строительных материалов. В п. Мохсоголлох запланировано создание палаточного городка первостроителей, «Центра инноваций в социальной сфере». В п. Нижний Куранах появится нефтеперерабатывающий завод «Куранах», запланирована модернизация асфальтобетонного завода, строительство завода железобетонных изделий и др.

Таким образом, анализ пространственной дифференциации расселения представляет важный компонент обеспечения социально-экономической безопасности развития территорий. Актуальность подобных исследований обусловлена такими явлениями, как усиление центростремительного вектора и, соответственно, диспропорций в пространственном развитии, а также связана с теми задачами, которые поставлены в Стратегии пространственного развития РФ.

В северных регионах, в том числе и в Республике Саха (Якутия), отмечаемый ранее рост городских поселений сменился на иной тренд к сокращению числа городских поселений при одновременном значительном сокращении сельских населенных пунктов. Происходит дальнейшее углубление территориальной концентрации населения; присутствуют внутрирегиональные центро-периферийные градиенты; население все более расселяется в региональных центрах и ближайших к ним районах, а остальные территории подвергаются депопуляции.

Перспективы тех или иных поселений, безусловно, определяются не только их демографическим потенциалом, но и экономическим потенциалом территорий. В этом аспекте вероятны благоприятные условия для возрождения некоторых арктических поселений, ранее являвшихся базами Северного морского пути, поселений, перспективных для участия в промышленном освоении минерально-сырьевых ресурсов или для размещения вооруженных сил. Все эти возможности напрямую связаны с перспективами освоения Арктики, интерес к которой обусловлен ее природно-сырьевым потенциалом и геополитической значимостью [6-8].

Говоря о монопрофильных поселениях, нельзя однозначно утверждать об их несостоятельности как своеобразной форме расселения населения. Возникновение моногородов на Севере связано со спецификой регионального развития северных территорий, ориентированного на добычу природных ресурсов, полезных ископаемых стратегического значения. В условиях, когда основным драйвером было освоение месторождений полезных ископаемых, формирование монопрофильных поселений было закономерным явлением. 
Ориентация на сырьевую экономику по-прежнему остается основным подходом в развитии северных и арктических территорий, несмотря на декларированность более диверсифицированного развития. Со- хранение такого подхода вряд ли будет способствовать как диверсификации экономики, так и созданию условий для комплексного развития системы расселения, в том числе и моногородов.

\title{
Литература
}

1. Мкртчян Н., Карачурина Л. Региональные столицы и глубинка // Демоскоп Weekly. № 575-576. 18 ноябр - 1 декабря 2013. Режим доступа: http://demoscope.ru/weekly/2013/0575/tema01.php (дата обращения: 27.01.2018).

2. Мостахова Т. С. Демографические аспекты развития сельских территорий Республики Саха (Якутия) // ЭКО. 2015. № 4. С. 138-143.

3. Лейзерович Е. Е. Опыт количественной оценки территориальной концентрации населения мира // Вопросы географии. Сб. 135: География населения и социальная география / отв. ред. А. И. Алексеев, А. А. Ткаченко. М.: Кодекс, 2013. С. 72-82.

4. Федорова Е. Н. Проблемы оптимизации городского расселения Республики Саха (Якутия) // Наука и образование. 2007. № 3. С. 114-117.

5. Карачурина Л. Б., Мкртчян Н. В. Изменение численности населения административных районов и городов России (1989-2010 гг.): центро-периферийные соотношения // Вопросы географии. Сб. 135: География населения и социальная география / отв. ред. А. И. Алексеев, А. А. Ткаченко. М.: Кодекс, 2013. С. 82-108.

6. Пахомов А. А., Мостахова Т. С. Современные вопросы освоения Арктики // Актуальные направления фундаментальных и прикладных исследований. Материалы VI международной научно-практической конференции (22-23 июня 2015). North Charleston, USA: CreateSpace, 2015. C. 216-218.

7. Мостахова Т. С. Сельские поселения Арктики: демографические аспекты устойчивого развития // Актуальные проблемы, направления и механизмы развития производительных сил Севера: материалы Четвертого Всероссийского научного семинара: часть І. Сыктывкар, 2014. С. 88-96.

8. Мостахова Т. С., Туманова Д. В. Арктика: проблемы освоения и воспроизводства населения (на примере Республики Саха (Якутия)) // Экономика, социология и право. 2015. № 1. С. 114-116.

\section{THE PROBLEM OF TERRITORIAL POPULATION CONCENTRATION AND THE ONE-INDUSTRY TOWNS IN THE NORTHERN REGION (THE REPUBLIC OF SAKHA (YAKUTIA) Tatyana S.Mostakhoval, @}

\author{
${ }^{1}$ Yakutsk Scientific Center of the Siberian Branch of the Russian Academy of Sciences, 2, Petrovsky St. , Yakutsk, \\ Russia, 677000 \\ @mostakhovats@mail.ru
}

Received 19.02.2018. Accepted 27.03.2018.

Keywords: spatial development, resettlement, Northern region, single-industry towns, Republic of Sakha (Yakutia).

\begin{abstract}
The resettlement of the population appears to be a significant factor in the sustainable development of the territory. The imbalances in spatial development that have been forming during a certain period of time concern mostly the imbalances between the center and the periphery, urban and rural settlements. This disproportion draws scientific attention to the processes of population concentration and the prospects for their development.

Over the past decades, the main trend in resettlement has been the flow of the population to the center and the negative peripheral dynamics. The deep transformational changes in Russia, which coincided with significant demographic changes, resulted in an increasing dichotomy between the focal point and the province.

In the Northern and Arctic regions, this tendency is reflected in a reduction in the number of settlements, both urban and rural. The dilution of the settlement network, together with the deepening of the territorial population concentration, lead to even greater depersonalization on the territory. Rural settlement downturn has been accompanied by certain changes in the character of urban settlements, where a significant proportion belongs to single-industry towns. The instability of the city-forming base poses a threat to the demographic potential of single-industry towns.

Northern ingle-industry towns owe their existence to the specifics of regional development that has always been focused on the extraction of strategically important
\end{abstract}


natural resources. They should not be evaluated only as an untenable form of spatial organization of the population. The current focus on the raw materials economy still prevails in the development of the Northern and Arctic territories, and it is unlikely that such an approach will contribute to either economic diversification or the creation of conditions for the integrated development of the settlement system, including single-industry towns.

For citation: Mostakhova T. S. Problemy territorial'noi kontsentratsii naseleniia i monogoroda v severnom regione (na primere Respubliki Sakha (Iakutiia)) [The Problem of Territorial Population Concentration and the One-Industry Towns in the Northern Region (the Republic of Sakha (Yakutia)]. Bulletin of Kemerovo State University. Series: Political, Sociological and Economic Sciences, no. 2 (2018): 28-32. DOI:10.21603/2500-3372-2018-2-28-32.

\section{References}

1. Mkrtchian N., Karachurina L. Regional'nye stolitsy i glubinka [The regional capital and the provinces]. Demoskop Weekly = Demoscope Weekly, no. 575-576 (18 November Kodeks 1 December 2013). Available at: http:// demoscope.ru/weekly/2013/0575/tema01.php (accessed 27.01.2018).

2. Mostakhova T. S. Demograficheskie aspekty razvitiia sel'skikh territorii Respubliki Sakha (Iakutiia) [Demographic aspects of development of rural territories of the Republic of Sakha (Yakutia)]. EKO = ECO, no. 4 (2015): 138-143.

3. Leizerovich E. E. Opyt kolichestvennoi otsenki territorial'noi kontsentratsii naseleniia mira [Experience of quantitative evaluation of the territorial concentration of the world's population]. Voprosy geografii. Sb. 135: Geografiia naseleniia i sotsial'naia geografiia [Questions of Geography. Sat. 135: Geography of the population and social geography]. Ed. Alekseev A. I., Tkachenko A. A. Moscow: Kodeks, 2013, 72-82.

4. Fedorova E. N. Problemy optimizatsii gorodskogo rasseleniia Respubliki Sakha (Iakutiia) [Problems of optimization of urban settlement of the Republic of Sakha (Yakutia)]. Nauka i obrazovanie = Science and education, no. 3 (2007): 114-117.

5. Karachurina L. B., Mkrtchian N. V. Izmenenie chislennosti naseleniia administrativnykh raionov i gorodov Rossii (1989-2010 gg.): tsentro-periferiinye sootnosheniia [The changes in the population of administrative districts and cities of Russia (1989-2010): center-periphery ratio]. Voprosy geografii. Sb. 135: Geografiia naseleniia i sotsial'naia geografia [Questions of Geography. Sat. 135: Geography of the population and social geography]. Ed. Alekseev A. I., Tkachenko A. A. Moscow: Kodeks, 2013, 82-108.

6. Pakhomov A. A., Mostakhova T. S. Sovremennye voprosy osvoeniia Arktiki [The modern development of the Arctic]. Aktual'nye napravleniia fundamental'nykh i prikladnykh issledovanii. Materialy VI mezhdunarodnoi nauchno-prakticheskoi konferentsii (22-23 iiunia 2015) [Actual directions of fundamental and applied research: Proc. VI Intern. Sc.-Prac. Conf. (June 22-23 2015)]. North Charleston, USA: CreateSpace, 2015, $216-218$.

7. Mostakhova T. S. Sel'skie poseleniia Arktiki: demograficheskie aspekty ustoichivogo razvitiia [Rural settlement in the Arctic: demographic aspects of sustainable development]. Aktual'nye problemy, napravleniia i mekhanizmy razvitiia proizvoditel'nykh sil Severa: materialy Chetvertogo Vserossiiskogo nauchnogo seminara [Actual problems, directions and mechanisms of development of the productive forces of the North: Proc. Fourth All-Russian Sc. Sem.]. Syktyvkar, part I (2014): 88-96.

8. Mostakhova T. S., Tumanova D. V. Arktika: problemy osvoeniia i vosproizvodstva naseleniia (na primere Respubliki Sakha (Iakutiia)) [The Arctic: problems of development and population reproduction (the Republic of Sakha (Yakutia))]. Ekonomika, sotsiologiia i pravo = Economics, sociology and law, no. 1 (2015): 114-116. 